\title{
Mood, Personality, and Behavior Changes During Treatment with Statins: A Case Series
}

\author{
Stephanie Cham $^{1,2} \cdot$ Hayley J. Koslik ${ }^{1}$ Beatrice A. Golomb ${ }^{1}$
}

Published online: 29 December 2015

(c) The Author(s) 2015. This article is published with open access at Springerlink.com

\begin{abstract}
Psychiatric adverse drug reactions (ADRs) have been reported with statin use, but the literature regarding statin-associated $\mathrm{mood} / \mathrm{behavioral} \mathrm{changes}$ remains limited. We sought to elicit information germane to natural history and characteristics of central nervous system/behavioral changes in apparent connection with statin and/or cholesterol-lowering drug use, and delineate mechanisms that may bear on an association. Participants (and/or proxies) self-referred with behavioral and/or mood changes in apparent association with statins completed a survey eliciting cholesterol-lowering drug history, character and impact of behavioral/mood effect, time-course of onset and recovery in relation to drug use/modification, cooccurrence of recognized statin-associated ADRs, and factors relevant to ADR causality determination. Naranjo presumptive ADR causality criteria were assessed. Participants $(n=12)$ reported mood/behavior change that commenced following statin initiation and persisted or progressed with continued use. Reported problems included violent ideation, irritability, depression, and suicide. Problems resolved with drug discontinuation and recurred with rechallenge where attempted. Eight met presumptive criteria for "probable" or "definite" causality; others had additional factors not considered in Naranjo criteria that bear on casual likelihood. (1) Simvastatin $80 \mathrm{mg}$ was
\end{abstract}

Beatrice A. Golomb

bgolomb@ucsd.edu

1 Department of Medicine, University of California, San Diego, 9500 Gilman Drive \# 0995, La Jolla, CA 92093-0995, USA

2 Present Address: Department of Obstetrics and Gynecology, Columbia New York Presbyterian, New York, NY 10032, USA followed in 5 days by irritability/depression culminating in suicide in a man in his 40s (Naranjo criteria: possible causality). (2) Simvastatin $10 \mathrm{mg}$ was followed within 2 weeks by depression in a woman in her 50s (probable causality). (3) Atorvastatin $20 \mathrm{mg}$ was followed in $\sim 1$ month by depression and irritability/aggression in a male in his 50s (probable causality). (4) Atorvastatin $10 \mathrm{mg}$ was followed in several months by aggression/irritability and depression culminating in suicide in a man in his $40 \mathrm{~s}$ (possible causality). (5) Fenofibrate + rosuvastatin (unknown dose), later combined with atorvastatin were followed in 1 month by aggression/irritability in a male in his 30s (probable causality). (6) Lovastatin (unknown dose and time-course to reaction) was followed by depression, dyscontrol of bipolar disorder, and suicide attempts in a male in his 40s (possible causality). (7) Atorvastatin $20 \mathrm{mg}$ was followed within 2 weeks by cognitive compromise, and nightmares, depression, and anxiety culminating in suicide in a man in his teens (definite causality). (8) Simvastatin $10 \mathrm{mg}$ was followed (time-course not recalled) by depression, aggression/irritability culminating in suicide in a man in his 60s (possible causality). (9) Simvastatin $20 \mathrm{mg}$ then atorvastatin $10 \mathrm{mg}$ were followed (time-course not provided) by irritability/aggression in a man in his $60 \mathrm{~s}$ (definite causality). (10) Atorvastatin 10 then 20 then $40 \mathrm{mg}$ were followed shortly after the dose increase by violent ideation and anxiety in a man in his 30 s (probable causality). (11) Atorvastatin $20 \mathrm{mg}$ and then simvastatin $20 \mathrm{mg}$ were followed in 2 weeks by aggression/irritability in a man in his 50s (definite causality). (12) Lovastatin, rosuvastatin, atorvastatin, and simvastatin at varying doses were followed as quickly as 1 day by aggression, irritability, and violent ideation in a man in his 40s (definite causality). Most had risk factors for statin ADRs, and cooccurrence of other, recognized statin ADRs. ADRs had 
implications for marriages, careers, and safety of self and others. These observations support the potential for adverse mood and behavioral change in some individuals with statin use, extend the limited literature on such effects, and provide impetus for further investigation into these presumptive ADRs. Potential mechanisms are reviewed, including hypothesized mechanisms related to oxidative stress and bioenergetics.

\section{Key Points}

Psychiatric adverse effects, altering mood, personality, and behavior, sometimes arise in patients receiving statins.

Statin psychiatric effects can include irritability/ aggression, anxiety or depressed mood, violent ideation, sleep problems including nightmares, and possibly suicide attempt and completion.

\section{Introduction}

Most adverse drug reaction (ADR) reporting focuses on non-behavioral health risks to the medication-taking individual; however, attention is increasingly given to druginduced behavioral and mood changes that may affect self or others. Drugs and medications with behavioral concerns include alcohol (best recognized) [1], but also varenicline [2-4], loratadine [5], mefloquine [6], tramadol [7, 8], isotretinoin [9], tricyclics [10], benzodiazepines [11, 12], and selective serotonin reuptake inhibitors (SSRIs) [13-16], among others [17]. Emerging evidence suggests such problems may occasionally arise with cholesterol-lowering drugs [18-20]. These drugs are widely prescribed and most prominently include statins (3-hydroxy-3-methylglutaryl coenzyme-A reductase inhibitors), which held the place of best-selling class of prescription drugs in the world and include the best-selling prescription drug in history [2124].

Neuropsychiatric ADRs of statins, including suicide and aggression, have been reported in pharmacovigilance databases [20, 25] and in adverse event reports and series [18, 19, 26]. Moreover, adverse behaviors have been reported in settings of low cholesterol [27-29]; and of lower omega-3 fatty acid levels (the omega-3 to omega- 6 ratio is reportedly reduced with statins) [30-32]. Both naturally low cholesterol and randomized assignment to cholesterol reduction in the pre-statin era have been reported to be linked to increased violent deaths [28, 33, 34], though statin randomization has not [35]. Recent randomized controlled trial (RCT) evidence indicating that statins can have bidirectional effects on aggression may be germane here: different mediating factors, including increased sleep problems and perhaps reduced testosterone, appear to drive effects in differing directions, and bidirectional effects on oxidative stress may also be speculated to do so. Nonetheless, the literature relating mood and behavioral changes to cholesterol-lowering drugs, and depicting the character and potential implications of adverse psychiatric effects with statins, remains relatively sparse [18, 20, 25, 36, 37]. Here we present 12 cases of mood and behavioral change apparently associated with lipid-lowering agents.

\section{Methods}

A total of 12 subjects and/or their family members (if the subject was deceased) who reportedly experienced mood and behavioral changes while receiving one or more statin, as identified by the subject and/or by family members, contacted our study group and provided survey information. Written informed consent was obtained from each participant (or proxy for deceased subjects) for inclusion of their case in this case series. These 12 represent a convenience sample, chosen because the neuropsychiatric problem was the primary complaint, because the nature or severity appeared to warrant representation in the literature, because the participant or proxy was amenable to inclusion (with proper de-identification), and because the aggregate number, 12, was small enough to allow inclusion of some individual detail, yet sufficient to illustrate a suite of potential issues.

Elicited information included demographic characteristics, drug(s) used (statin and concomitant medications), dose(s), time-course of mood and behavior change relative to drug use (onset, duration, recovery), character of symptoms, and open-ended narrative of the impact of behavior, mood, and/or personality changes. We inquired whether a modification to the treatment regimen occurred-such as changes in dose, drug discontinuation, and drug rechallenge-and the impact on symptoms. Recognized risk factors for statin ADRs, and development of other recognized statin ADRs, were also elicited. Information for each case is presented in tabular form.

Cases were assessed for adherence to presumptive causality criteria using the published Naranjo drug ADR causality classification. This employs a point system of positive and negative causality points to estimate the probability of an ADR, with a score $\geq 9$ deemed to indicate "definite" ADR causality, 5-8 "probable", 1-4 "possible", and $\leq 0$ "doubtful" [38]. For all participants, adverse event causality was at least "possible", since psychiatric 
and behavioral reactions to statins or cholesterol reduction bear biological plausibility and prior reports. "Probable" causality was limited to those who experienced occurrence following drug initiation, had the drug discontinued, and improved following drug discontinuation. "Definite" causality assignments were limited to those who, in addition to recovery with discontinuation, were rechallenged with the drug, and experienced symptom recurrence.

\section{Results}

Information on drug, drug dose, reported mood and behavioral effect, factors supporting a causal connection, other statin symptoms, family history of psychiatric problems associated with statin use, and presence of risk factors for statin adverse effects are listed in Table 1. Cases commonly involved more than one psychiatric element (Table 2). An expanded description of each case is provided (Table 3). Marked change in mood and/or behavior was commonly noted, in some instances leading to tragic consequences. In some cases, proximal mood or behavioral changes arising with cholesterol-lowering agents led to the addition of psychiatric medications, and a role for these psychotropic medications in behavioral sequelae cannot be excluded. Behavioral/mood findings often accompanied muscle, cognitive, or other better recognized statin adverse effects [39-41]. Some participants had family members who also had experienced psychiatric adverse effects attributed to statins. Several participants exhibited compelling on-off-on reproducibility of findings.

Based on Naranjo presumptive criteria for ADR causality, eight cases qualified as bearing a "probable" or "definite" causality designation. The four cases designated "possible" are included because of factors not considered in Naranjo criteria that bear on likelihood of a causal connection. (As was said for a drug bearing a similar spectrum of behavioral adverse behaviors, "the clear temporal relationship, lack of prior history of this behavior, and unusual nature of these events strengthens the accumulating scientific evidence" [2]). Each patient exhibited persistent absence of the symptom prior to administration of the statin, followed by persistent presence while receiving the statin (days to years). One possible exception was a man with bipolar disorder; however, he had manifested years of stability and good control since initiation of lithium until statin initiation, which resulted in loss of psychiatric stability persisting for the years he was receiving statins until his death. Prospects for a causal connection were buttressed by an adverse behavioral change while receiving statins in a first-degree relative who also experienced dechallenge-rechallenge support (family history and genetics are risk factors for statin problems)
[46-52]. A total of $75 \%$ of cases were accompanied by other symptoms with a confirmed relation to statin use, including muscle symptoms [41, 53-60], cognitive problems [40, 61-63], and dermatologic reactions [39]. Additionally, $50 \%$ of cases had factors previously shown to be linked to an elevated risk of statin ADRs, such as thyroid conditions [39].

\section{Discussion}

\section{Summary}

Behavioral and psychiatric changes in the cases presented range from violent nightmares to aggression, mood/personality change, violent or homicidal ideation (in some instances culminating in suicide), each in apparent association with statin use. The temporal association between the drug initiation and mood and behavior change, and again between drug discontinuation and resolution of symptoms where this occurred, suggests a causal connection in a number of these cases. Notable mood and behavioral changes for all patients or introduction of serious psychiatric events began after drug initiation. The latency profile is consistent with that for other statin ADRs that share common mechanisms [40, 41], and bear RCT support [39, 59, 61, 62]. Symptoms persisted or progressed with continued use in all cases. Those able to discontinue the drug experienced resolution of symptoms. For those in whom rechallenge was possible, symptoms recurred. The presence of ADRs and risk factors with a confirmed relation to statin ADRs is consistent with common pathophysiological factors, hypothesized to underlie many statin adverse effects, extending to behavioral effects [39]. (12 cases are included; for those interested in knowledge of other cases of this kind, a 13th case, involving a physician with behavioral changes while receiving statins and leading to professional review, is planned for inclusion in a separate manuscript on statin adverse effects in physicians).

\section{Explanation of Findings; Comparison/Contrast with Other Findings in Literature}

Though a relation of statins to instances of behavior alteration may seem counterintuitive, it fits with a body of existing literature. Observationally, lower cholesterol has been linked to greater violence (including aggression, suicide, homicide, violence) in many studies, including prospective longitudinal studies [28, 29, 64, 65]. Behavioral consequences of lipid-lowering medications have been reported for non-statin treatments, including fibrates [20] (implicated in case 5), with support extending to metaanalyses of RCTs showing significantly increased violent 
1 Page 4 of 13

S. Cham et al.

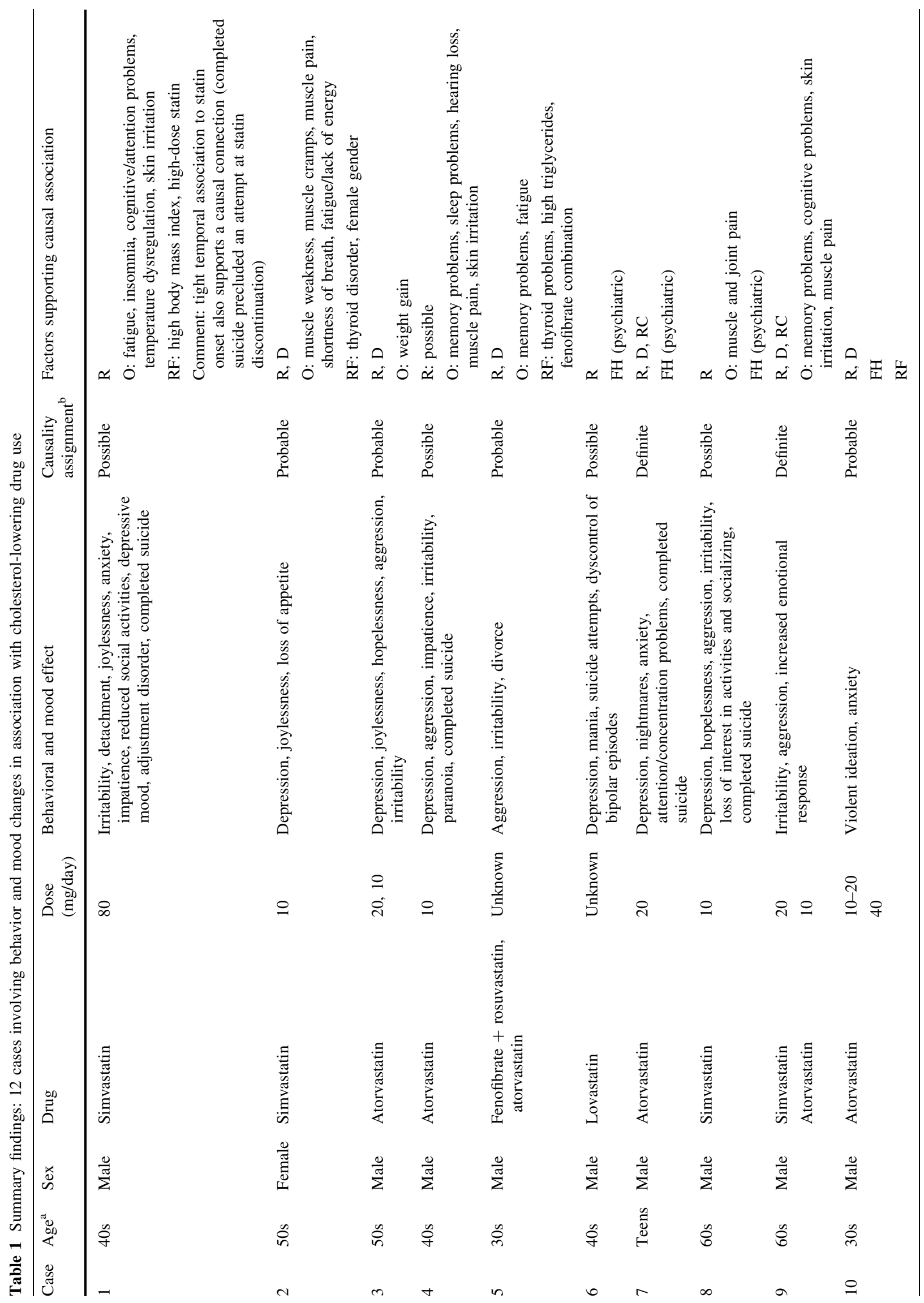

$\triangle$ Adios 


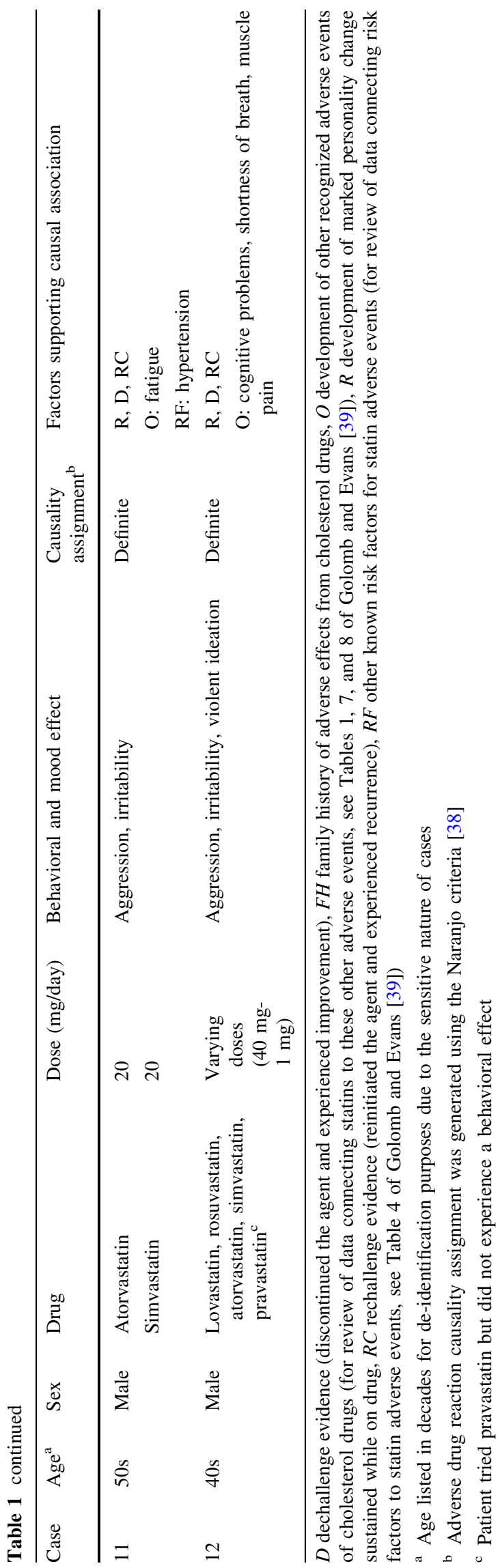

death [28, 33, 34]. RCT meta-analysis in the statin era did not support an increase in violent death on average (indeed the point estimate was lower, though not significantly) [35]. RCT patient selection may be one factor: excess violent deaths on pre-statin lipid drugs were preferentially evident in those with risk factors for violence-e.g., alcohol, psychiatric history, and non-compliance [66]. Of note, there was no evidence of more patients with these characteristics in the cholesterol-lowering group, but the excess of events emphasized these patients. Psychiatric histories, alcohol/substance use, and low conscientiousness are risk factors for lower compliance, so may lead to exclusion with compliance run-ins, but are also risk factors for adverse behaviors, so vulnerable individuals might be preferentially excluded [67]. Relative exclusion may affect detection of risk in two ways. First, the same fractional (relative) risk change will lead to a greater number affected, and more power to show a change, in those at higher risk (a doubling of nothing is still nothing) [68]. Second, the fractional risk change itself may be greater in a behaviorally vulnerable subset (effect modification): illustrating this point, the odds ratios risk of psychiatric events with mefloquine use was reported to be 3.8 among those without a psychiatric history, versus apparently double that (8.0) in those with a psychiatric history [6].

Other factors may also explain this. Randomized trial evidence examining statin effects on aggression provides potential insights: statins (vs. placebo) promoted both average significant increases and reduction in aggression, in different groups [69]. Typical effects in men (particularly in men who were both younger and less aggressive at baseline) were toward reduced aggression [69], with older age and female sex shifting the distribution. Simvastatin has been shown to both significantly lower testosterone [70] and worsen sleep problems on average [43]. (It may also promote sleep apnea in some [71]). For men receiving simvastatin, the magnitude of each of these effects significantly predicted the change in aggression, in opposite directions [69]. Sleep problems and sleep apnea are elsewhere linked to irritability [72-74], as well as aggression and violence [75]. Lower testosterone in some settings is linked to lower aggression and violence [76, 77].

Other mechanisms may be theorized. Low central serotonin has been linked to low cholesterol and to aggression [28, 78, 79]. However, whole blood serotonin (which correlates inversely to central serotonin) did not predict aggression in mediation analysis within a randomized trial [69]. We also hypothesize that effects on aggression, and perhaps mood problems on statins, may be linked to oxidative stress [80] and inter-related mitochondrial dysfunction (which has been linked to temper disorders) [81]. The explanation accords with our finding that behavioral adverse effects commonly co-occur with 
Table 2 Psychiatric elements present in more than one case

\begin{tabular}{|c|c|c|c|c|c|c|c|c|}
\hline Case & $\begin{array}{l}\text { Short temper/ } \\
\text { aggression/ } \\
\text { irritability }\end{array}$ & Violent ideation & $\begin{array}{l}\text { Completed } \\
\text { suicide }\end{array}$ & Depression & $\begin{array}{l}\text { Joyless/ } \\
\text { hopeless }\end{array}$ & $\begin{array}{l}\text { Reduced } \\
\text { socializing/ } \\
\text { activity }\end{array}$ & Anxiety & Impatience \\
\hline 1 & $\mathrm{x}$ & & $\mathrm{x}$ & $\mathrm{x}$ & $\mathrm{x}$ & $\mathrm{x}$ & $\mathrm{x}$ & $\mathrm{x}$ \\
\hline 2 & & & & $\mathrm{x}$ & $\mathrm{x}$ & & & \\
\hline 3 & $\mathrm{x}$ & & & $\mathrm{x}$ & $\mathrm{x}$ & & & \\
\hline 4 & $\mathrm{x}$ & & $\mathrm{x}$ & $\mathrm{x}$ & & & & $\mathrm{x}$ \\
\hline 5 & $\mathrm{x}$ & & & & & & & \\
\hline 6 & & & & $\mathrm{x}$ & & & & \\
\hline 7 & & & $\mathrm{x}$ & $\mathrm{x}$ & & & $\mathrm{x}$ & \\
\hline 8 & $\mathrm{x}$ & & $\mathrm{x}$ & $\mathrm{x}$ & $\mathrm{x}$ & $\mathrm{x}$ & & \\
\hline 9 & $\mathrm{x}$ & & & & & & & \\
\hline 10 & & $\mathrm{x}$ & & & & & $\mathrm{x}$ & \\
\hline 11 & $\mathrm{x}$ & & & & & & & \\
\hline 12 & $\mathrm{x}$ & $\mathrm{x}$ & & & & & & \\
\hline Total & 8 & 2 & 4 & 7 & 4 & 2 & 3 & 2 \\
\hline
\end{tabular}

Manifestations reported by only one participant include paranoia, detachment, suicidal ideation, loss of appetite, nightmares, attention/concentration problems, increased emotional response, mania, and dyscontrol of bipolar disorder

better known statin adverse effects, with the documented relation of better known statin adverse effects to oxidative stress and mitochondrial dysfunction [39], and with the documented connection of mitochondrial dysfunction to a range of psychiatric problems [82-87].

Other hypothetical mechanisms of potential relevance, such as the role of cholesterol in synapse formation or membrane function, and myelin production have been reviewed elsewhere [40,88], but in contrast to mechanisms cited above, triangulating evidence for a role is currently lacking.

The explanation accords with our finding that behavioral adverse effects commonly co-occur with better known statin adverse effects, for which a relation to oxidative stress and mitochondrial dysfunction has been elucidated [39]. Mitochondrial dysfunction has a documented connection to a range of psychiatric problems [82-87], and may also contribute to behavioral change with statin-induced oxidative damage.

More lipophilic statins have better brain penetration [89, 90], though all statins have some ability to cross the bloodbrain barrier [91]. Whether this is important for central effects of the kinds described is unknown, since peripheral effects can have central consequences-and since prooxidant effects of statins, which are linked to the occurrence of statin adverse effects [92], also raise blood-brain barrier penetrability [93, 94]. Each of the patients in our report experienced problems while receiving at least one of simvastatin, atorvastatin, or lovastatin, which are lipophilic statins. However, most involved atorvastatin and simvastatin, which have also historically been the most frequently prescribed statins. This, and the lack of a defined base population in which statin prescribing rates are known, obviates our ability to comment on whether lipophilicity is relevant to these effects.

\section{Limitations}

This study has the limitations inherent to all case series: data are observational, which constrains causal inference. However, a profound change in state while receiving a drug, particularly with dechallenge-rechallenge support, strengthens the case for causality. There is no defined base population or control group, precluding calculation of rates and risk ratios, and occurrence of adverse neuropsychiatric effects in these cases, even if presumed causal, has no inherent implications for usual effects of statins on the outcomes reported-nor do usual effects have necessary implications to individual ones. Rather, this case series underscores that statins may in specific individuals promote adverse behavioral, mood, and personality changes, irrespective of whether behavioral (or mood) effects are on average favorable, adverse, or neutral. Even reporting rates relative to other ADRs may be a challenge to gauge meaningfully for neuropsychiatric problems, because these may be particularly sensitive, and may go unreported. In an analysis of emails abstracting statin ADRs mentioned spontaneously, mood or personality problems were spontaneously related as part of the ADR complex in a minority, but in a survey directly asking about each of a list of symptoms the participant attributed to statins, among those self-selected for having at least one such symptom, a majority cited a neuropsychiatric effect. (However, in the latter, there is 
Table 3 Description of twelve mood/behavior cases associated with cholesterol-lowering drug use

Case Case history

1 Case 1 , a professional ${ }^{\text {a }}$ male in his 40 s with a history of psoriasis and two negative stress SPECT tests, with no personal or family history of psychiatric illness, was placed on simvastatin $80 \mathrm{mg}$ for hyperlipidemia (TC $262 \mathrm{mg} / \mathrm{dL}$, TRG $123 \mathrm{mg} / \mathrm{dL}$, HDL $35 \mathrm{mg} / \mathrm{dL}$, and LDL $202 \mathrm{mg}$ / dL). No concomitant medications were being taken

By 5 days after initiation of high-dose simvastatin ( $80 \mathrm{mg}$ : a dose for which there is now a US FDA advisory [42]), his wife noted development of marked, uncharacteristic behavior changes, including a "darker change in affect", with relative loss of his previously bright personality and sense of humor. His wife describes him as having been an avid cook who also enjoyed substantive conversation; he lost interest in both following statin initiation. These altered personality and behavior characteristics progressed over the ensuing months, with manifestations including irritability, detachment, attention problems, joylessness, anxiety, fatigue, impatience, insomnia, and reduced social interest/activities, accompanied by nonpsychiatric symptoms of altered temperature regulation (feeling cold while others felt hot) and "muddled thinking", [39]). As a former editor of the Law Review at his university's Law School, he was perceived to have brilliant career prospects. He was successful in a demanding job, but the marked cognitive changes seriously affected his work performance, engendering significant work-related stress. Approximately 2 months after statin initiation, modestly elevated ALT levels were noted (64 and 72 units/L). He was diagnosed with non-alcoholic fatty liver disease. 6 months after statin initiation, he sought a psychiatrist, with the chief complaint of depression; his mental status was evaluated and a diagnosis of adjustment disorder and depressed mood was made

He had no familial or previous personal history of psychiatric illness. Risk factors for psychiatric illness included occupational stress; however, this appeared to be substantially a consequence of his newly impaired cognition. Cholesterol levels after 7 months of treatment were TC $172 \mathrm{mg} / \mathrm{dL}$, TRG $158 \mathrm{mg} / \mathrm{dL}$, HDL $38 \mathrm{mg} / \mathrm{dL}$, and LDL $102 \mathrm{mg} / \mathrm{dL}$. Over the next 3 months, he had bi-monthly visits with a social worker that focused on job-related stress, while concurrently family members continued to note a change in personality and decreased sociability. 1 month later, a rash unrelated to his psoriasis appeared on both arms. 2 days after the rash, he was prescribed temazepam 15-30 mg by a psychiatrist for sleep problems that included insomnia, nausea, and tightness in the chest, which had surfaced in the previous months. During the psychiatric medication evaluation, the psychiatrist noted "his thought processes are well-organized and expressed in a concise linear fashion ... the patient does not exhibit paranoid or grandiose delusional thinking ... he is not a danger to himself or others ... his insight and judgment are overall intact"

7 days later, 9 months after initiating statins, he committed what family members describe as a "completely unexpected" suicide with a gunshot wound to the head and self-inflicted wounds to the wrists and neck. Toxicology reports reveal no alcohol or commonly abused drugs in his system at the time of death

Factors meriting note: no familial history of psychiatric illness, no history of alcohol abuse. Fatty liver is tied to metabolic syndrome factors, which are strong risk factors for statin adverse effects and may sometimes be consequences of them [39]. Sleep problems, noted here, are a reported adverse effect of simvastatin [43], as are GI problems and skin rashes, which were also noted while receiving statins [39]. Benzodiazepines, given due to sleep problems arising on statins, may have been a contributory or mediating factor. (Hereafter, concurrent AEs consistent with statin effects are listed only in Table 1). In our AE reporting system, temperature dysregulation is also a commonly reported statin adverse effect

2 Case 2 is a female in her 50s with a history of autoimmune thyroid disorder, taking $100 \mu \mathrm{g}$ of levothyroxine for treatment. She was prescribed $10 \mathrm{mg} /$ day of simvastatin for treatment of borderline hyperlipidemia (TC $205 \mathrm{mg} / \mathrm{dL}$ )

Within 2 weeks of statin initiation, she noted extreme muscle cramps that would wake her during the night, as well as other symptoms including muscle weakness (e.g., decreased walking ability), muscle pain (in the shoulders), and shortness of breath, and she began taking ibuprofen to manage the pain. This was followed by marked change in mood/emergence of depression. Manifestations of this change included wanting to leave her husband (despite over 20 years of a happy marriage), joylessness (felt that there was a "veil" between her and others, and the inability to feel happy at her daughter's wedding), desire for isolation, wanting to quit her job, and loss of appetite and energy. Approximately 1-2 months after statin initiation, cholesterol levels were taken: TC $180 \mathrm{mg} / \mathrm{dL}$, TRG $50 \mathrm{mg} / \mathrm{dL}$, HDL $52 \mathrm{mg} / \mathrm{dL}$, and LDL $118 \mathrm{mg} / \mathrm{dL}$

After 3 months of statin treatment with adverse mood/personality change, she discontinued the statin (primarily due to the depression) and reported her symptoms to her physician

Mood improvement was evident by 1 month after discontinuation of lipid therapy, and full recovery had occurred by 3 months. A longer time, approximately 1 year after statin discontinuation, was required for full resolution of muscle symptoms. 16 months after statin discontinuation TC is $209 \mathrm{mg} / \mathrm{dL}$

Factors meriting note: no familial history of psychiatric illness, no history of alcohol abuse

3 Case 3, a male professional ${ }^{\mathrm{a}}$ in his late $50 \mathrm{~s}$, began atorvastatin treatment at $20 \mathrm{mg} / \mathrm{day}$ for hyperlipidemia and CAD prevention (TC $215 \mathrm{mg} / \mathrm{dL}$ and mildly elevated LDL), which he reduced to $10 \mathrm{mg} /$ day because he "did not feel well" on $20 \mathrm{mg}$. On the $10-\mathrm{mg} / \mathrm{day}$ dose, his TC was $170 \mathrm{mg} / \mathrm{dL}$ and LDL was approximately $90 \mathrm{mg} / \mathrm{dL}$

Approximately 1 month after initiating atorvastatin, his wife noted new adverse mood and personality changes: increased irritability, periods of mild depression, general anhedonia with a 10-lb weight gain. He initially attributed these symptoms to stress and change in job. Approximately 2 years after statin treatment initiation, he was diagnosed with acid reflux and began lansoprazole. The severity of his depression and perceived irritability worsened, with manifestations including feelings of isolation, hopelessness, depression, and "passive-aggressive" anger with himself and those around him. His wife noted a change in facial expression (always appearing to have an "angry face") as well as a change in personality, and worried he was unhappy with the marriage

After several months of combined treatment, with intensified adverse mood/personality change, he discontinued the statin

Within 5 days after statin discontinuation, he had noted marked recovery from symptoms, including a return of his sense of humor and feelings of happiness, increased productivity, and noted a better relationship with his wife. In addition, he observed a more relaxed facial expression had replaced his angry facial appearance that had been characteristic while receiving statin treatment 
Table 3 continued

Case Case history

4 Case 4, a male in his 40s, full Professor at a major university, and internationally regarded scientist, with a family history of cardiovascular disease was treated with atorvastatin $10 \mathrm{mg}$ for hyperlipidemia (TC $210 \mathrm{mg} / \mathrm{dL}$ ). Concomitant medications included flonase. He is described as a previously strong, open, and spiritual person who was beloved by students and a treasured confidante for many of his friends and family. He was reportedly a major figure in his field

Following initiation of statin use, he experienced extreme uncharacteristic changes in personality and behavior. Initially ascribed to stress at work, these symptoms continued to progress, and by approximately 6 months on statins he and family members had become clearly aware of changes. He developed insomnia (a reported statin adverse effect). Family members also began to notice signs of lethargy and deactivation (e.g., staring into the ceiling for hours), as well as irritability and aggression (e.g., agitation and loss of temper at work): both of which were highly uncharacteristic. Additionally, he experienced notable memory problems, including a loss of sense of direction for places he had been to previously. He was prescribed zolpidem $5 \mathrm{mg}$ for the insomnia, which he took only on rare occasions. 2-3 months before his death, he began exercising and eating more fruit in an effort to combat his general feeling of malaise while receiving the statin treatment. He was found to have contacted a statin adverse effect website. Other potential statin-related side effects he experienced that he reported to the website included hearing problems, eczema, muscle pains, and temporary memory loss. It was later discovered that 2 months prior to his death he also began logging on to a suicide website under an assumed name where users assisted one another in attempts, and had set the date and method for his own suicide. Family members noted this as a very strange discovery, as deceptiveness was uncharacteristic of him; he had previously been known for an open, honest, and candid personality. 1 month before his death, behavioral changes became increasingly evident, and family members particularly noted his "disheveled appearance" contrasting with his normally well-groomed habits. Approximately 2 weeks prior to his death, he had a cholesterol reading of $120 \mathrm{mg} / \mathrm{dL} .1$ week prior, he was found furtively moving helium tanks in the household, which he claimed were for a family member's birthday. 3 days before his suicide, he began exhibiting notable paranoia; manifestations included panic when his children were not present in the same room and continual fear that someone may be after him and his family

Following approximately 1 year of lipid therapy and adverse personality change, he went to work, and in the evening called his wife to run errands at the store stating he would be home afterwards. Later that evening he committed asphyxial suicide by inhalation of helium in conjunction with the use of zolpidem and alprazolam. (Benzodiazepines are also linked to adverse behavioral sequelae. Here initiated for sleep problems arising following statin use. Though he reportedly took these "rarely", a contribution by these agents cannot be excluded)

Factors meriting note: no history of alcohol abuse, and no familial history of psychiatric illness

5 Case 5 is a professional ${ }^{\mathrm{a}}$ male in his late $30 \mathrm{~s}$ with an advanced degree who was receiving levothyroxine for hypothyroidism. He was placed on fenofibrate, which was then successively combined with rosuvastatin or atorvastatin to treat hyperlipidemia, including elevated TRGs (TC $209 \mathrm{mg} / \mathrm{dL}$, TRG $620 \mathrm{mg} / \mathrm{dL}$, and HDL $23 \mathrm{mg} / \mathrm{dL}$ )

1 month into lipid treatment, he began to notice personality changes, felt "on edge", and exhibited increased temper directed particularly toward his wife. Other manifestations included reading/interpreting facial expressions as more hostile [44], himself exhibiting a hostile facial expression, increased temper on the road, and verbal fighting with his wife. Other statin side effects noted were fatigue and memory problems. His wife reported he was easily provoked, became cynical, began having road rage (e.g., honking when others were not), had a "short fuse", instigated fights for no reason, and was lethargic at work when he was previously driven to succeed. Relatives also noted his increased anger and irritability. His wife sought solace outside the marriage, then separated and filed for divorce, citing the anger, irritability, and increased arguments

After 16 months of lipid treatment accompanied by adverse personality change, he discontinued lipid medications

By 1 week after drug discontinuation, he had already noted improvement in temper and increased patience, as well as increased energy, reduction in sleeping hours required, and reduction in appetite (which had increased on statins). 3 weeks after discontinuation, he also noted he was able to be more physically active, had increased sweating ability, modest weight loss, reduced anxiety/ "worry", and reduced irritability. When we followed up with him longer term, he sounded markedly different relative to the first call. His personality and voice patterns were lively, enthusiastic, and joyful with laughter, and was engaged and interested in ideas (vs. previously perceived as much more intense and introverted). As his wife had commenced other involvements, divorce proceedings remained underway

6 Case 6 was a male in his late 40s with a long history of bipolar disorder who had responded remarkably well to lithium. His family describes him as successful and brilliant; he was the president of an international organization and managed his own business. He was treated with cholestyramine and niacin for familial hyperlipidemia and a family history of cardiovascular disease, without apparent psychiatric sequelae. Following years of successful lithium therapy and psychiatric stability, he was switched to lovastatin

Shortly after he commenced statin treatment, his longstanding psychiatric stability was extinguished. He began experiencing major episodes of mania and depression. Manifestations included inability to get out of bed and loss of interest in work. These episodes had a drastic impact on his occupation; he gave up on his business and although highly qualified was unable to find another job because of his depression. He attempted to combat his depression with exercise, drumming, writing, attending seminars, seeing doctors, and undergoing therapy. He began to lose interest in activities he normally enjoyed, and the episodes also began straining his marriage of 10 years and his relationship with his children

Following 1 year of statin therapy with sustained psychiatric dyscontrol, he made his first suicide attempt. A little over 3.5 years after commencing the statin, his TC was $133 \mathrm{mg} / \mathrm{dL}$. At this time he began to undergo psychotherapy 6 days a week, and was unsuccessfully treated with a variety of antidepressants, but continued lovastatin and lithium treatment throughout. Two more suicide attempts occurred during this period of time, and approximately 6 months later he experienced a fatal stroke. Of note, a first-degree relative reported experiencing behavioral changes with statin use

Factors meriting note: family history of psychiatric statin side effects, family and personal history of psychiatric disorders, no history of alcohol abuse 
Table 3 continued

Case Case history

$7 \quad$ Case 7 was a male in his late teens who commenced atorvastatin $20 \mathrm{mg}$ for familial hyperlipidemia. He had a family history of psychiatric illness and adverse behavioral reaction to statins. His mother states that, prior to statin initiation, he was a "gracious, loving, and kind" person and good student, beloved by his teachers

Within 2 weeks of statin initiation, he began experiencing nightmares with homicidal thoughts; manifestations included nightmares involving guns and knives, which in one instance was violent enough to wake him and provoke him to jump out of a window. Normally a student who wanted to excel, he began experiencing attention and concentration problems, which progressed to development of severe difficulty with reading within months of starting the drug, which affected his school work. After 6 months receiving statin treatment, he was tested for and diagnosed with severe attention deficit disorder, for which there had been no evidence prior to statin initiation. He was treated with psychostimulants, including methylphenidate and amphetamines. Soon after he was diagnosed with depression and began seeing a therapist and commenced citalopram use. He stopped the psychostimulants within weeks as he "did not like how he felt on it", and discontinued the antidepressants within 8-9 months. Other manifestations included sleep walking, agitation, and anxiety with test taking

Following over 2 years of statin use and persistent behavioral/cognitive problems, he discontinued statin use, and family members noted rapid marked improvement in personality and cognitive function, including resolution of nightmares, restoration of his prior happier disposition, resumption of ability to concentrate and restoration of the ability to read. These improvements remained (stable and/or progressive) for the 6 weeks he remained off statin therapy

After 6 weeks off statins with sustained improvement, he resumed statin treatment, and within days the violent nightmares, difficulty with concentration, and depression had reemerged. By 2 weeks after reintroduction of the statin (2.5 years after first commencing statins), he had purchased a gun, and committed suicide with a self-inflicted gunshot wound

Factors meriting note: family history of statin psychiatric side effects, family history of psychiatric disorders, no history of alcohol abuse

Case 8 was a male in his 60s with a history of heart attack, triple bypass, and angioplasty. He had no psychiatric history, and family members described him, pre-statin, as a strong-headed and lively personality, who was well known in his community for being social. He owned a small business, was a member of a local sports team, and was active in local politics. He was placed on simvastatin 10 mg; concomitant medications included torasemide, propranolol, and nitroglycerin

After commencing statins, he experienced new and marked changes in personality: his family declared he was "not himself". His wife noted increased irritability as well as a short temper, and stated that their marriage of several years was becoming "difficult". His daughter also noted that he gradually began to isolate himself and avoid social situations, including socializing with friends and going to family functions; this became progressively worse during treatment. Family members stated he became increasingly overwhelmed by situations he would normally not, and had also adopted a demeanor of hopelessness. A year and half after his statin initiation, he began to note joint and muscle problems

Approximately 2 years after commencing the statin, after some troubles with his business, he committed suicide by a self-inflicted gunshot wound. Notably, two family members (his sister and his nephew) had also reported experiencing depression and mood changes in conjunction with statin use

Factors meriting note: family history of statin psychiatric side effects, no history of alcohol abuse

9 Case 9 is a male professional ${ }^{\mathrm{a}}$ in his $60 \mathrm{~s}$ who commenced simvastatin $20 \mathrm{mg}$ (concomitant medications include valsartan and omeprazole) for a TC of $253 \mathrm{mg} / \mathrm{dL}$, LDL $169 \mathrm{mg} / \mathrm{dL}$, HDL $48 \mathrm{mg} / \mathrm{dL}$, and TRG $178 \mathrm{mg} / \mathrm{dL}$

Following statin initiation, he began to note extreme irritability. Manifestations included a short temper, road rage, and snapping at his wife over minor problems. His wife also noted his change in mood and mentioned he seemed exceedingly "grumpy". In addition, he noted he became more emotional (e.g., would unexplainably tear up while reading a novel or watching a movie) and felt light-headed and "not right", both of which he stated were unlike his usual personality. He continued statin treatment and his symptoms persisted for over a year and a half. During this time, cholesterol levels were TC $175 \mathrm{mg} / \mathrm{dL}$, LDL $92 \mathrm{mg} / \mathrm{dL}$, HDL $49 \mathrm{mg} / \mathrm{dL}$, and TRG $170 \mathrm{mg} / \mathrm{dL}$. Other noted adverse effects included memory loss (including diagnosed transient global amnesia), cognitive problems, and a dermatologic reaction. He sought to discontinue the statin, but the brief effort was aborted when he was placed on atorvastatin $10 \mathrm{mg}$ after a diagnosis of a carotid stenosis. The adverse personality changes persisted, and were newly accompanied by muscle pain in the quadriceps

Following 8 months of treatment on atorvastatin and over 2 years on statins, with persistent adverse personality change, he discontinued treatment due to the changes in personality and memory

By 1 week after discontinuation, he noted significantly reduced irritability and temper (and a "mellower" personality), as well as a resolution of his skin rash (TC $225 \mathrm{mg} / \mathrm{dL}$, LDL $143 \mathrm{mg} / \mathrm{dL}$, HDL $53 \mathrm{mg} / \mathrm{dL}$, and TRG $144 \mathrm{mg} / \mathrm{dL}$ ). The improvement has been sustained on long-term followup. Approximately 1 year after discontinuing the statin, he notes he remains a "much happier camper" off statins, much more "mellow" and less prone to quick anger. He observes that during his half-hour commute to work he no longer expresses himself loudly at other drivers. Additionally, his wife also commented he no longer is sharp towards her. He now seeks to manage his cholesterol through diet and exercise

Factors meriting note include glucose intolerance and significant environmental exposures when younger, no familial history of psychiatric illness

10 Case 10 is a male professional ${ }^{\mathrm{a}}$ in his late 30 s with familial hyperlipidemia and no psychiatric history. His dose of atorvastatin was increased over a short time from 10 to 20 and then $40 \mathrm{mg}$

Within weeks of the dose increase, he experienced new anxiety and externally directed violent ideation that was deeply disturbing. (At his preference, additional details will not be given). These symptoms persisted. He communicated with our study group to inquire whether the statin dose change could play a role. We felt the possibility of a statin connection could not be excluded, given the close temporal relation of dose increase to symptom onset, on a backdrop of previously stable state with no prior suggestion of similar symptoms. He elected to do a trial off statins

Following several months on the higher-dose statin, with deeply disturbing violent ideation sustained throughout these months, he discontinued statin treatment

The violent ideation abated promptly and had resolved completely by 2 weeks off the statins. He has remained without hint of recurrence on longterm follow-up (several years later)

Factors meriting note: family history of statin side effects 
Table 3 continued

Case Case history

11 Case 11 is a male in his $50 \mathrm{~s}$ who began atorvastatin $20 \mathrm{mg}$ for hyperlipidemia (concomitant medications include lisinopril and hydrochlorothiazide). He then switched to simvastatin $20 \mathrm{mg}$

Approximately 2 weeks after the switch to simvastatin he noted no change; however, his wife cited notable fatigue and mood changes. In addition to his inactivity, she stated he was extremely irritable and had extreme mood swings, describing him as "explosive". The two had arguments almost every day and his wife commented the verbal exchanges would become aggressive. As he continued simvastatin use, she noted his irritability progressively worsened

After the husband-wife pair discussed the issue with his general practitioner, following persistent problems while on simvastatin, he discontinued his cholesterol drug use

2-3 weeks after drug discontinuation, his wife noted he was less fatigued and displayed a more calm and peaceful demeanor. He did not notice any changes. In a 1-month follow-up, he noted he was slightly less fatigued, and his wife stated his mood had become noticeably more "mellow" and patient, with fewer arguments and mood swings

He subsequently resumed statin use, with recurrence of reported marked increase in irritability cited by the wife (arising $\sim 1-2$ months after statin reintroduction), who stated these were sufficient to seriously threaten their marriage

12 Case 12 is a male in his mid-40s with a history of familial hypercholesterolemia and a family history of cardiovascular disease. He began lovastatin treatment for elevated LDL levels. He reportedly had a very calm temperament prior to initiating statins

Immediately, 1 day after starting the statin, he developed markedly uncharacteristic severe irritability and aggression and cognitive dysfunction. Manifestations included anger directed toward his wife and family members

Based on the notable changes in mood, 3 days later his wife suggested he discontinue the statins, and his aggression quickly resolved

3 years later, he began trials of the lowest dosages of each of several statins available to manage his cholesterol. Following each of atorvastatin, simvastatin, and rosuvastatin, he developed similar changes in mood, including aggression, irritability, lack of patience, and violent ideation. Manifestations included arguing and yelling directed at his wife, children, and clients at work, affecting his family and business. He noted increased aggressive behavior while driving, and "unnerving" violent ideation towards others. Mood changes were virtually immediate with initiating each statin: he stated his wife could determine whether he was on the statin based on his mood and behavior changes. In addition to his mood changes, he also experienced mental confusion. He attempted to reduce the dosages of each statin to as low as $1 \mathrm{mg}$ and change his diet, but continued to experience side effects

He discontinued each statin for 2 weeks at a time, with his anger and irritability resolving virtually immediately, and returning when the statins were resumed. He experienced the most prominent side effects with rosuvastatin, followed by the atorvastatin, and described both as "mindaltering drugs"

His final switch to pravastatin $40 \mathrm{mg}$ resulted in no notable mood or behavior changes, and he successfully continued its use. However, 7 years later, he discontinued its use due to shortness of breath and foot pain diagnosed as plantar fasciitis, which resolved following discontinuation Several years later, he noted similar symptoms after ingesting bergamot, which inhibits HMG-CoA reductase and lowers cholesterol [45]

Information for cases 1, 4, 6, 7, and 8 (all of whom are deceased) was obtained via proxy surveys completed by close family members. "Factors meriting note" designates considerations that relate to likelihood of adverse effect occurrence or protection (e.g., risk factors or their absence)

$A E$ adverse event, $A L T$ alanine aminotransferase, $C A D$ coronary artery disease, $G I$ gastrointestinal, $H D L$ high-density lipoprotein cholesterol, $H M G-C o A$ 3-hydroxy-3-methylglutaryl coenzyme A, LDL low-density lipoprotein cholesterol, SPECT single-photon emission computed tomography, TC total cholesterol, TRG triglycerides

${ }^{a}$ Professional here refers to those with advanced degrees: MDs, PhDs, or JDs (except for deceased individuals, identifying information is kept general due to the sensitive nature of the effects). A further (13th) case involving behavioral adverse effects is planned for inclusion in a separate case series on physicians with statin adverse effects

no gauge of severity; and physical problems can themselves contribute to some level of psychic distress).

Some of our participants had underlying conditions (such as a psychiatric disorder) that can themselves lead to an adverse outcome; however, as above, the odds ratios for risk of psychiatric events due to a drug can be magnified in the presence of a psychiatric history [6]. Consistent with this, most of the excess cases of violent death arising in the active treatment, cholesterol-lowering arms in a pre-statin-era analysis of randomized trials had other risk factors for violent death [66]; since those risk factors themselves were not shown to be increased in the active treatment group, this underscores that individuals with such issues may represent a vulnerable subgroup (as with mefloquine). As a further analogy, an analysis of rhabdomyolysis cases in the San Diego area showed that typical instances involved the confluence of more than one risk factor-consistent again with an increase in the odds of an event "due to" each agent, in the presence of the other [95]. In our cases, factors such as the temporal relation to statin use, and concurrence of other statincompatible ADRs increases the prospects for causality with statins.

Data rely on self-report. However, patient self-reports of ADRs can be a valuable and reliable tool [96-100], and-if heeded-may hasten recognition of important ADRs [101]; such benefits have led to standardized implementation of patient reporting for EU-based pharmacovigilance databases [102]. Self-selection of participants is inherent to studies with volunteer patients; however, for studying those with ADRs, whether or not they reflect typical effects, observed effects are important. 


\section{Conclusions}

Though statins are widely tolerated, they may be among the growing list of prescription agents that, in some participants, may increase the risk of serious psychiatric events and/or behavioral changes. In the cases cited here, these adverse experiences posed risks to the safety of self and otherssometimes, tragically, adversely affecting marriages and careers, or culminating in death. The possibility of such ADRs, even if rare, should be recognized by physicians who prescribe cholesterol-lowering drugs, such that if personality or behavior changes arise, the drug can be included in considerations of etiology and treatment. This series extends the modest literature on behavior and psychiatric changes apparently associated with cholesterol-lowering treatment. These findings further the evidence that cholesterol-lowering drugs should be added to the list of agents that bear consideration when new irritability, or aggressive or violent behavioral changes arise.

Acknowledgments The authors gratefully acknowledge the time and effort of the participants who shared their information, and thank all those who assisted with the Statin Effects Study. All authors had full access to all the data in the study. Dr. Cham takes final responsibility for the integrity of the data and the accuracy of the analysis. Dr. Cham is now employed by the Department of Obstetrics and Gynecology, Columbia New York Presbyterian.

\section{Compliance with Ethical Standards}

Funding The ADR database and survey from which these findings were drawn was funded by a Robert Wood Johnson Generalist Physician Faculty Scholar Award to Dr. Golomb. We are grateful for individual donations that contributed to that larger research effort. Contributing parties had no role in the design or conduct of the study; collection, management, analysis and interpretation of data; or preparation, review, or approval of this manuscript.

Conflict of interest Beatrice A. Golomb, Hayley J. Koslik, and Stephanie Cham have no conflicts of interest that are directly relevant to the content of this study.

Patient consent Written informed consent was obtained from each participant (or proxy for deceased subjects) for inclusion of their case in this case series.

Open Access This article is distributed under the terms of the Creative Commons Attribution-NonCommercial 4.0 International License (http://creativecommons.org/licenses/by-nc/4.0/), which permits any noncommercial use, distribution, and reproduction in any medium, provided you give appropriate credit to the original author(s) and the source, provide a link to the Creative Commons license, and indicate if changes were made.

\section{References}

1. Zabel GE. Alcohol and aggression: violence prone drivers preventing passing maneuvers. Blutalkohol. 1996;33:84-93.
2. Moore TJ, Glenmullen J, Furberg CD. Thoughts and acts of aggression/violence toward others reported in association with varenicline. Ann Pharmacother. 2010;44:1389-94.

3. Food and Drug Administration. Varenicline (marketed as Chantix) information. 2009. http://www.fda.gov/Drugs/DrugSafety/ PostmarketDrugSafetyInformationforPatientsandProviders/ucm 106540.htm. Accessed July 2010.

4. Kasliwal R, Wilton LV, Shakir SA. Safety and drug utilization profile of varenicline as used in general practice in England: interim results from a prescription-event monitoring study. Drug Saf. 2009;32:499-507.

5. Routledge PA, Lindquist M, Edwards IR. Spontaneous reporting of suspected adverse reactions to antihistamines: a national and international perspective. Clin Exp Allergy. 1999;29(Suppl 3):240-6 (discussion 7-50).

6. van Riemsdijk MM, Sturkenboom MC, Pepplinkhuizen L, Stricker BH. Mefloquine increases the risk of serious psychiatric events during travel abroad: a nationwide case-control study in the Netherlands. J Clin Psychiatry. 2005;66:199-204.

7. Food and Drug Administration. Important drug warning-Ultram (tramadol). 2010. http://www.fda.gov/downloads/Safety/ MedWatch/.../UCM213265.pdf. Accessed July 2010.

8. Pinkofsky HB, Woodward RA, Reeves RR. Mood alterations and tramadol. Am J Psychiatry. 1996;153:843-4.

9. Kontaxakis VP, Skourides D, Ferentinos P, Havaki-Kontaxaki BJ, Papadimitriou GN. Isotretinoin and psychopathology: a review. Ann Gen Psychiatry. 2009;8:2.

10. Rampling D. Aggression: a paradoxical response to tricyclic antidepressants. Am J Psychiatry. 1978;135:117-8.

11. Lion JR, Azcarate CL, Koepke HH. "Paradoxical rage reactions" during psychotropic medication. Dis Nerv Syst. 1975;36:557-8.

12. Hall RC, Zisook S. Paradoxical reactions to benzodiazepines. $\mathrm{Br}$ J Clin Pharmacol. 1981;11(Suppl 1):99S-104S.

13. Fergusson D, Doucette S, Glass KC, Shapiro S, Healy D, Hebert $\mathrm{P}$, et al. Association between suicide attempts and selective serotonin reuptake inhibitors: systematic review of randomised controlled trials. Br Med J. 2005;330:396.

14. Medawar C, Herxheimer A. A comparison of adverse drug reaction reports from professionals and users, relating to risk of dependence and suicidal behavior. Int J Risk Safety Med. 2003;16:5-19.

15. Food and Drug Administration. FDA Proposes new warnings about suicidal thinking, behavior in young adults who take antidepressant medications. 2007. http://www.fda.gov/News Events/Newsroom/PressAnnouncements/2007/ucm108905.htm. Accessed July 2010.

16. Breggin P. Suicidality, violence and mania caused by selective serotonin reuptake inhibitors (SSRIs): a review and analysis. Int J Risk Safety Med. 2003;16:31-49.

17. Stewart JT. Paradoxical aggressive effect of propranolol in a patient with Huntington's disease. J Clin Psychiatry. 1987;48:385-6.

18. Golomb BA, Kane T, Dimsdale JE. Severe irritability associated with statin cholesterol-lowering drugs. QJM. 2004;97:229-35.

19. Duits N, Bos FM. Depressive symptoms and cholesterol-lowering drugs. Lancet. 1993;341:114.

20. Tatley M, Savage R. Psychiatric adverse reactions with statins, fibrates and ezetimibe: implications for the use of lipid-lowering agents. Drug Saf. 2007;30:195-201.

21. IMS Health. 2001. http://www.imshealth.com/public/structure/ dispcontent/1,2779,1009-1009-110296,00.html. Accessed June 2001.

22. IMS Health. US top ten products by prescriptions. 2002. http:// www.imshealth.com/public/structure/dispcontent/1,2779,13431343-144004,00.html. Accessed 19 April 2002. 
23. IMS Health. Lipitor leads the way in 2003. 2004. http://www. ims-global.com/insight/news_story/0403/news_story_040316. htm. Accessed 23 May 2005.

24. IMS Health. IMS global insights-IMS retail drug monitor December 2007. 2007. http://www.imshealth.com/web/ content/0,3148,64576068_63872702_70260998_83746585,00. html. Accessed 2 May 2008.

25. Buajordet I, Madsen S. Olsen H [Statins-the pattern of adverse effects with emphasis on mental reactions. Data from a national and an international database]. Tidsskr Nor Laegeforen. 1997; 117:3210-3.

26. Duits N. Bos FM [Psychiatric disorders with use of simvastatin]. Nederlands Tijdschrift voor Geneeskunde. 1993;137:1312-5.

27. Zhang J, Muldoon MF, McKeown RE, Cuffe SP. Association of serum cholesterol and history of school suspension among school-age children and adolescents in the United States. Am J Epidemiol. 2005;161:691-9.

28. Golomb BA. Cholesterol and violence: Is there a connection? Ann Int Med. 1998;128:478-87.

29. Golomb BA, Stattin H, Mednick S. Low cholesterol and violent crime. J Psychiatr Res. 2000;34:301-9.

30. Conklin SM, Manuck SB, Yao JK, Flory JD, Hibbeln JR, Muldoon MF. High \{omega -6 and low \{omega -3 fatty acids are associated with depressive symptoms and neuroticism. Psychosom Med. 2007;69:932-4.

31. Conklin SM, Harris JI, Manuck SB, Yao JK, Hibbeln JR, Muldoon MF. Serum omega-3 fatty acids are associated with variation in mood, personality and behavior in hypercholesterolemic community volunteers. Psychiatry Res. 2007;152:1-10.

32. Harris JI, Hibbeln JR, Mackey RH, Muldoon MF. Statin treatment alters serum n-3 and n-6 fatty acids in hypercholesterolemic patients. Prostaglandins Leukot Essent Fatty Acids. 2004;71:263-9.

33. Muldoon M, Rossouw J, Manuck S, Gluech C, Kaplan J, Kaufmann P. Low or lowered cholesterol and risk of death from suicide and trauma. Metabolism. 1993;42:45-56.

34. Muldoon MF, Manuck SB, Matthews KA. Lowering cholesterol concentrations and mortality: a quantitative review of primary prevention trials. BMJ. 1990;301:309-14.

35. Muldoon MF, Manuck SB, Mendelsohn AB, Kaplan JR, Belle SH. Cholesterol reduction and non-illness mortality: metaanalysis of randomised clinical trials. BMJ (Clinical Research Ed). 2001;322:11-5.

36. Olson MB, Kelsey SF, Matthews KA, Bairey Merz CN, Eteiba $\mathrm{W}$, McGorray SP, et al. Lipid-lowering medication use and aggression scores in women: a report from the NHLBI-sponsored WISE study. J Womens Health (Larchmt). 2008:17:187-94.

37. Tuccori M, Lapi F, Testi A, Coli D, Moretti U, Vannacci A, et al. Statin-associated psychiatric adverse events: a case/noncase evaluation of an Italian database of spontaneous adverse drug reaction reporting. Drug Saf. 2008;31:1115-23.

38. Naranjo CA, Busto U, Sellers EM, Sandor P, Ruiz I, Roberts EA, et al. A method for estimating the probability of adverse drug reactions. Clin Pharmacol Ther. 1981;30:239-45.

39. Golomb BA, Evans MA. Statin adverse effects: a review of the literature and evidence for a mitochondrial mechanism. Am J Cardiovasc Drugs. 2008;8:373-418.

40. Evans MA, Golomb BA. Statin-associated adverse cognitive effects: survey results from 171 patients. Pharmacotherapy. 2009;29:800-11.

41. Cham S, Evans MA, Denenberg JO, Golomb BA. Statin-associated muscle-related adverse effects: a case series of 354 patients. Pharmacotherapy. 2010;30:541-53.
42. Food and Drug Administration. FDA drug safety communication: new restrictions, contraindications, and dose limitations for Zocor (simvastatin) to reduce the risk of muscle injury. 2011. http://www.fda.gov/Drugs/DrugSafety/ucm256581.htm. Accessed 24 Sept 2015.

43. Golomb BA, Kwon EK, Criqui MH, Dimsdale JE. Simvastatin but not pravastatin affects sleep: findings from the UCSD Statin Study. Circulation. 2007;116:II_847.

44. Guggenheim CB, Foster HG Jr. Serum cholesterol and perception of anger and sadness. Psychol Rep. 1995;77:1343-5.

45. Mollace V, Sacco I, Janda E, Malara C, Ventrice D, Colica C, et al. Hypolipemic and hypoglycaemic activity of bergamot polyphenols: from animal models to human studies. Fitoterapia. 2011;82:309-16.

46. Ahmad Z. Statin intolerance. Am J Cardiol. 2014;113:1765-71.

47. Francesca Notarangelo M, Marziliano N, Antonietta Demola M, Pigazzani F, Guidorossi A, Angelica Merlini P, et al. Genetic predisposition to atorvastatin-induced myopathy: a case report. J Clin Pharm Ther. 2012;37:604-6.

48. Reilly D, Cham S, Golomb BA. First-degree relatives with behavioural adverse effects on statins. BMJ Case Rep. 2011. doi:10.1136/bcr.09.2011.4758.

49. Vladutiu GD. Genetic predisposition to statin myopathy. Curr Opin Rheumatol. 2008;20:648-55.

50. Needham M, Mastaglia FL. Statin myotoxicity: a review of genetic susceptibility factors. Neuromuscul Disord. 2014;24:4-15.

51. Ruano G, Thompson PD, Windemuth A, Seip RL, Dande A, Sorokin A, et al. Physiogenomic association of statin-related myalgia to serotonin receptors. Muscle Nerve. 2007;36:329-35.

52. Oh J, Ban MR, Miskie BA, Pollex RL, Hegele RA. Genetic determinants of statin intolerance. Lipids Health Dis. 2007;6:7.

53. Phillips PS, Haas RH, Bannykh S, Hathaway S, Gray NL, Kimura BJ, et al. Statin-associated myopathy with normal creatine kinase levels. Ann Intern Med. 2002;137:581-5.

54. Sinzinger H, Schmid P, O'Grady J. Two different types of exercise-induced muscle pain without myopathy and CK-elevation during HMG-Co-enzyme-A-reductase inhibitor treatment. Atherosclerosis. 1999;143:459-60.

55. Sinzinger $H$. Does vitamin E beneficially affect muscle pains during HMG-Co-A-reductase inhibitors without CK-elevation. Atherosclerosis. 2000;149:225.

56. Sinzinger H, Lupattelli G, Chehne F, Oguogho A, Furberg CD. Isoprostane 8-epi-PGF2alpha is frequently increased in patients with muscle pain and/or CK-elevation after HMG-Co-enzymeA-reductase inhibitor therapy. J Clin Pharm Ther. 2001;26:303-10.

57. Vladutiu GD, Simmons Z, Isackson PJ, Tarnopolsky M, Peltier WL, Barboi AC, et al. Genetic risk factors associated with lipid-lowering drug-induced myopathies. Muscle Nerve. 2006;34:153-62.

58. Vladutiu GD, Tabone E. Mitochondrial disease in patients with exercise intolerance. N Engl J Med. 2000;342:438-40.

59. Golomb BA, Evans MA, Dimsdale JE, White HL. Effects of statins on energy and fatigue with exertion: results from a randomized controlled trial. Arch Intern Med. 2012;172:1180-2.

60. Golomb BA, Koperski S. Who becomes weak on statins? Effect modification exposed in a RCT by risk factor compounding. Circulation. 2013;127:AP072.

61. Muldoon MF, Barger SD, Ryan CM, Flory JD, Lehoczky JP, Matthews KA, et al. Effects of lovastatin on cognitive function and psychological well-being. Am J Med. 2000;108:538-46.

62. Muldoon MF, Ryan CM, Sereika SM, Flory JD, Manuck SB. Randomized trial of the effects of simvastatin on cognitive functioning in hypercholesterolemic adults. Am J Med. 2004;117:823-9. 
63. Wagstaff LR, Mitton MW, Arvik BM, Doraiswamy PM. Statinassociated memory loss: analysis of 60 case reports and review of the literature. Pharmacotherapy. 2003;23:871-80.

64. Partonen T, Haukka J, Virtamo J, Taylor PR, Lonnqvist J. Association of low serum total cholesterol with major depression and suicide. Br J Psychiatry. 1999;175:259-62.

65. Repo-Tiihonen E, Halonen P, Tiihonen J, Virkkunen M. Total serum cholesterol level, violent criminal offences, suicidal behavior, mortality and the appearance of conduct disorder in Finnish male criminal offenders with antisocial personality disorder. Eur Arch Psychiatry Clin Neurosci. 2002;252:8-11.

66. Wysowski DK, Gross TP. Deaths due to accidents and violence in two recent trials of cholesterol-lowering drugs. Arch Intern Med. 1990;150:2169-72.

67. Stilley CS, Sereika S, Muldoon MF, Ryan CM, Dunbar-Jacob J. Psychological and cognitive function: predictors of adherence with cholesterol lowering treatment. Ann Behav Med. 2004:27:117-24.

68. Silberberg JS, Henry DA. The benefits of reducing cholesterol levels: the need to distinguish primary from secondary prevention. 1. A meta-analysis of cholesterol-lowering trials. Med J Aust. 1991;155(665-6):9-70.

69. Golomb BA, Dimsdale JE, Koslik HJ, Evans MA, Lu X, Rossi S, et al. Statin effects on aggression: results from the UCSD statin study, a randomized control trial. PLoS One. 2015;10:e124451.

70. Golomb BA, Koperski S. Testosterone change relates to lipid change on statins. Circulation. 2013;127:AMP17.

71. Cham S, Gill K, Koperski S, Golomb BA. Improvement in sleep apnoea associated with switch from simvastatin to pravastatin. BMJ Case Rep. 2009. doi:10.1136/bcr.05.2009.1875.

72. Flemons WW, Tsai W. Quality of life consequences of sleepdisordered breathing. J Allergy Clin Immunol. 1997;99:S750-6.

73. Oginska H, Pokorski J. Fatigue and mood correlates of sleep length in three age-social groups: school children, students, and employees. Chronobiol Int. 2006;23:1317-28.

74. Barnes M, Houston D, Worsnop CJ, Neill AM, Mykytyn IJ, Kay $\mathrm{A}$, et al. A randomized controlled trial of continuous positive airway pressure in mild obstructive sleep apnea. Am J Respir Crit Care Med. 2002;165:773-80.

75. Kamphuis J, Meerlo P, Koolhaas JM, Lancel M. Poor sleep as a potential causal factor in aggression and violence. Sleep Med. 2012;13:327-34.

76. Olweus D, Mattsson A, Schalling D, Low H. Circulating testosterone levels and aggression in adolescent males: a causal analysis. Psychosom Med. 1988;50:261-72.

77. Olweus D, Mattsson A, Schalling D, Low H. Testosterone, aggression, physical, and personality dimensions in normal adolescent males. Psychosom Med. 1980;42:253-69.

78. Golomb BA, Tenkanen L, Alikoski T, Niskanen T, Manninen V, Huttunen $\mathrm{M}$, et al. Insulin sensitivity markers: predictors of accidents and suicides in Helsinki Heart Study screenees. J Clin Epidemiol. 2002;55:767-73.

79. Kaplan JR, Shively CA, Fontenot MB, Morgan TM, Howell SM, Manuck SB, et al. Demonstration of an association among dietary cholesterol, central serotonergic activity, and social behavior in monkeys. Psychosom Med. 1994;56:479-84.

80. Patki G, Atrooz F, Alkadhi I, Solanki N, Salim S. High aggression in rats is associated with elevated stress, anxiety-like behavior, and altered catecholamine content in the brain. Neurosci Lett. 2015;584:308-13.

81. Destee A, Martin JJ, Muller JP, Scholte HR, Verier A, Largilliere C, et al. Mitochondrial myopathy. Encephalopathy with lactic acidosis and cerebral infarction. Rev Neurol (Paris). 1989;145:37-48.

82. Gardner A, Boles RG. Symptoms of somatization as a rapid screening tool for mitochondrial dysfunction in depression. Biopsychosoc Med. 2008;2:7.
83. Shao L, Martin MV, Watson SJ, Schatzberg A, Akil H, Myers RM, et al. Mitochondrial involvement in psychiatric disorders. Ann Med. 2008;40:281-95.

84. Fattal O, Link J, Quinn K, Cohen BH, Franco K. Psychiatric comorbidity in 36 adults with mitochondrial cytopathies. CNS Spectr. 2007;12:429-38.

85. Odawara M. Mitochondrial gene abnormalities as a cause of psychiatric diseases. Nucleic Acids Res Suppl. 2002;2:253-4.

86. Triggs WJ, Roe CR, Rhead WJ, Hanson SK, Lin SN, Willmore LJ. Neuropsychiatric manifestations of defect in mitochondrial beta oxidation response to riboflavin. J Neurol Neurosurg Psychiatry. 1992;55:209-11.

87. Suzuki T, Koizumi J, Shiraishi H, Ofuku K, Sasaki M, Hori T, et al. Psychiatric disturbance in mitochondrial encephalomyopathy. J Neurol Neurosurg Psychiatry. 1989;52:920-2.

88. Tuccori M, Montagnani S, Mantarro S, Capogrosso-Sansone A, Ruggiero E, Saporiti A, et al. Neuropsychiatric adverse events associated with statins: epidemiology, pathophysiology, prevention and management. CNS Drugs. 2014;28:249-72.

89. Botti RE, Triscari J, Pan HY, Zayat J. Concentrations of pravastatin and lovastatin in cerebrospinal fluid in healthy subjects. Clin Neuropharmacol. 1991;14:256-61.

90. Saheki A, Terasaki T, Tamai I, Tsuji A. In vivo and in vitro blood-brain barrier transport of 3-hydroxy-3-methylglutaryl coenzyme A (HMG-CoA) reductase inhibitors. Pharm Res. 1994;11:305-11.

91. Cibickova L. Statins and their influence on brain cholesterol. J Clin Lipidol. 2011;5:373-9.

92. Sinzinger H, Lupattelli G, Chehne F. Increased lipid peroxidation in a patient with CK-elevation and muscle pain during statin therapy. Atherosclerosis. 2000;153:255-6.

93. Haorah J, Ramirez SH, Schall K, Smith D, Pandya R, Persidsky Y. Oxidative stress activates protein tyrosine kinase and matrix metalloproteinases leading to blood-brain barrier dysfunction. J Neurochem. 2007;101:566-76.

94. Lochhead JJ, McCaffrey G, Quigley CE, Finch J, DeMarco KM, Nametz N, et al. Oxidative stress increases blood-brain barrier permeability and induces alterations in occludin during hypoxiareoxygenation. J Cereb Blood Flow Metab. 2010;30:1625-36.

95. Linares L, Golomb B, Jaojoco J, Sikand H, Phillips PS. The modern spectrum of rhabdomyolysis: drug toxicity revealed by creatine kinase screening. Curr Drug Saf. 2009. doi:CDS ABS09 [pii].

96. Fisher S, Bryant SG, Kent TA, Davis JE. Patient drug attributions and postmarketing surveillance. Pharmacotherapy. 1994;14:202-9.

97. Fisher S, Bryant SG, Kluge RM. New approaches to postmarketing surveillance. Psychopharmacology (Berl). 1986;90:347-50.

98. Fisher S, Bryant SG. Postmarketing surveillance: accuracy of patient drug attribution judgments. Clin Pharmacol Ther. 1990;48:102-7.

99. Fisher S, Bryant SG. Postmarketing surveillance of adverse drug reactions: patient self-monitoring. J Am Board Fam Pract. 1992;5:17-25.

100. Jarernsiripornkul N, Krska J, Richards RM, Capps PA. Patient reporting of adverse drug reactions: useful information for pain management? Eur J Pain. 2003;7:219-24.

101. Basch $\mathrm{E}$. The missing voice of patients in drug-safety reporting. N Engl J Med. 2010;362:865-9.

102. Stenver DI. Pharmacovigilance: when to report adverse reactions In: Thomsen HS, Webb JAW, editors. Contrast media: safety issues and ESUR guidelines. 2nd ed. Berlin: Medical Radiology, Springer; 2009. p. 21-3. 